\title{
Work in dry cleaning and the incidence of cancer of the oral cavity, larynx, and oesophagus
}

\author{
Thomas L Vaughan, Patricia A Stewart, Scott Davis, David B Thomas
}

\begin{abstract}
Objectives-To investigate whether employment in dry cleaning, and potential exposure to perchloroethylene (PCE), were associated with increased risk of carcinoma of the oral cavity and pharynx, larynx, oesophagus, and gastric cardia. Methods-Two population based casecontrol studies were carried out. There were 491 cases of carcinoma of the oral cavity and pharynx, 235 of the larynx, and 404 of the oesophagus and gastric cardia. 724 controls were selected by random digit dialing. Personal interviews ascertained information on lifetime job histories, cigarette use, alcohol consumption, and other potential risk factors. The probability and level of exposure to PCE were estimated from the scientific literature.
\end{abstract}

Results-People who worked in dry cleaning tended to consume less alcohol and cigarettes than the general population. The adjusted odds ratio (OR) associated with ever having worked in dry cleaning was $1.6(95 \%$ confidence interval $(95 \% \mathrm{CI})$ $=0.6$ to 4.4 ) for all cancer types together. The strongest associations were with laryngeal (OR 2.7; 95\% CI 0.6 to 10.9) and oesophageal squamous cell carcinomas (OR 3.6; 95\% CI 0.5 to 27.0). For laryngeal cancer, the relative risk increased with number of years employed in the dry cleaning industry $(P=0.14$. The two cases of oesophageal squamous cell carcinomas had worked in dry cleaning for only a short time. Analyses of subsites showed higher risks for supraglottic laryngeal cancer (OR 5.7; 95\% CI 1.0 to 32.1 ) and cancer of the tongue (OR 2.3; $95 \%$ CI 0.4 to 12.6). Analyses of exposure to PCE yielded similar results.

Conclusions-These findings could easily be explained by chance; nevertheless, they are consistent with previous reports of excess risk of oesophageal, laryngeal, and tongue cancer, and suggest that previous studies of dry cleaners that could not control for alcohol and cigarette use may have underestimated the relative risks of such cancers.

(Occup Environ Med 1997;54:692-695)
Keywords: neoplasms; larynx; oral cavity; oesophageal; gastric cardia; adenocarcinoma; dry cleaning; perchloroethylene

Several million people work in the dry cleaning industry worldwide. The most common solvent in current use is perchloroethylene (PCE), a known animal carcinogen. Cohort studies of dry cleaners suggest an increased risk of mortality from oesophageal cancer, and to a lesser extent, cancer of the larynx and tongue. Dry cleaning involves the use of organic solvents to clean garments and other textiles. Stoddard solvent and then carbon tetrachloride were the most common solvents used until the 1960 s, when PCE came into widespread use. ${ }^{1}$ The experimental findings that exposure to PCE and carbon tetrachloride can cause cancer in animals have raised the possibility that dry cleaners and others occupationally exposed to these chemicals may have increased risk of cancer.' Supporting evidence comes from two cohort studies of dry cleaners that found twofold increases in risk of oesophageal cancer. ${ }^{23}$ The many people worldwide working in dry cleaning, estimated at several million, make this a considerable public health question. ${ }^{1}$

We analysed detailed occupational histories from two population based case-control studies to find whether employment in the dry cleaning industry, and associated potential exposure to PCE, increased the risk of upper aerodigestive tract cancers after controlling for cigarette and alcohol use.

\section{Materials and methods}

Incident cases were identified by the cancer surveillance system of the Fred Hutchinson Cancer Research Center, a population based cancer registry covering a 13 county area of western Washington. Cases were interviewed as part of two studies that used identical data collection methods. Both included men and women between the ages of 20 and 74 at diagnosis and resident in one of the three largest counties. The first study included people diagnosed between September 1983 and February 1987 with any histological type of cancer arising in the (a) oral cavity or pharynx (excluding salivary gland and nasopharynx), (b) larynx, or (c) oesophagus or gastric cardia. The second 
study included people diagnosed between March 1987 and November 1990 with adenocarcinoma of the oesophagus or gastric cardia.

The response rates (percentage of eligible cases successfully interviewed) were as follows: oral cavity $85.2 \%$; larynx $80.8 \%$; and oesophagus and gastric cardia $82.9 \%$. For the present report, non-epithelial and non-specified cancers were excluded. The cancers of the oesophagus and gastric cardia were further classified into squamous cell (international classification of diseases (ICD-O) histology codes $805 x-808 x)$ and adenocarcinomas (ICD-O 8140-8560). To retain comparability with controls, cases without telephones at the date of diagnosis were excluded. We analysed 1130 primary cancers that occurred in 1120 people; 10 people had two cancers each included in these analyses.

Random digit dialing was used to identify controls, who were frequency matched to the age (in five-year groups) and sex distribution of the cases. Overall, $95.4 \%$ of residential households were successfully screened, and $80.3 \%$ of eligible controls were interviewed, yielding 724 for analysis. Additional details about the methods and subject characteristics have been reported previously. ${ }^{4-6}$

With interviews in person, we obtained information on each job held for six months or more, including employer, type of business, job title, typical activities in that job, and employment dates. We also inquired about history of occupational exposure to solvents, and collected information on race, education, tobacco use, and alcohol intake. If a case had died, the closest next of kin was interviewed. This occurred for $7.2 \%$ of cases with laryngeal cancer, $18.7 \%$ with oral and pharyngeal cancer, and $33.2 \%$ with oesophageal and gastric cardiac cancer.

Thirty seven separate jobs in dry cleaning, including retail shops, dry cleaning plants, and institutions, were reported by 24 subjects. For 12 of the jobs, subjects also reported exposure to solvents. The three dry cleaners that we contacted used PCE to clean clothes on the premises in 1995. Without knowledge of case status, we estimated the probability that PCE was used in each job and the eight hour time weighted average (TWA) exposure to PCE in that job, based on the literature. ${ }^{7-20}$ The decade of work was used to classify probabilities of exposure to PCE as follows: before 1940 unlikely $(<5 \%) ; 1940$ to 1959 medium (20$50 \%$ ), and 1960 to 1989 high (> 50\%). Individual jobs were assigned eight hour TWAs as follows: cleaners and operators $(n=18) 40$ parts per million (ppm); pressers and counter workers $(\mathrm{n}=16) 7 \mathrm{ppm}$; others (including a delivery truck driver, book-keeper, and consultant) $(\mathrm{n}=3) 3 \mathrm{ppm}$. We also assessed probabilities of exposure to other dry cleaning solvents, including Stoddard solvent, carbon tetrachloride, petroleum based solvents, and trichloroethylene. However, separate analysis of other solvents was not feasible due to the homogeneity of exposure over the period in which most subjects worked, and high correlations with the probabilities of exposure to PCE.

Duration of employment in dry cleaning occupations and cumulative exposure (the product of duration and eight hour TWA) to PCE were calculated. Odds ratios (ORs) and $95 \%$ confidence intervals (95\% CIs) were obtained from conditional logistic regression models taking into account the matching factors. The reference group for all analyses was people who had never reported working in the dry cleaning industry. The subjects' previous use of cigarettes and alcohol, education, and reference date were adjusted for in all analyses. Adjustment for race did not change the risk estimates. Subjects were classified into never smokers, former smokers, and current smokers, with current smokers further classified by pack-years $(1-19,20-39$, and $\geqslant 40) .^{5}$ Alcohol intake was classified by average number of drinks per week into those drinking $<7,7-13,14-20$, and $\geqslant 21$. The confounding effects of alcohol and cigarettes also were explored in stratified analyses with conditional maximum likelihood estimates of the OR and exact $95 \%$ CIs. Tests for differences in alcohol and smoking histories among controls by a his-

Odds ratios associated with work in the dry cleaning industry and potential exposure to perchloroethylene

\begin{tabular}{|c|c|c|c|c|c|c|c|c|c|c|c|c|c|c|c|c|}
\hline & \multirow{3}{*}{$\underset{n}{\text { Contr }}$} & \multicolumn{15}{|l|}{ Cases } \\
\hline & & \multicolumn{3}{|c|}{ All cases } & \multicolumn{3}{|c|}{ Oral cavity } & \multicolumn{3}{|c|}{ Larynx } & \multicolumn{3}{|c|}{$\begin{array}{l}\text { Oesophagus } \\
\text { squamous cell }\end{array}$} & \multicolumn{3}{|c|}{$\begin{array}{l}\text { Oesophagust } \\
\text { adenocarcinoma }\end{array}$} \\
\hline & & $n$ & $O R^{*}$ & $(95 \% C I)$ & $n$ & $O R^{*}$ & $(95 \% C I)$ & $n$ & $O R^{*}$ & $(95 \% C I)$ & $n$ & $O R^{*}$ & $(95 \% C I)$ & $n$ & $O R^{*}$ & $(95 \% C I)$ \\
\hline \multicolumn{17}{|c|}{ Employed in dry cleaning industry: } \\
\hline Never & 716 & 1104 & 1.0 & & 484 & 1.0 & & 230 & 1.0 & & 107 & 1.0 & & 293 & 1.0 & \\
\hline Ever & 8 & 16 & 1.6 & $(0.6-4.4)$ & 7 & 1.2 & $(0.3-4.6)$ & 5 & 2.7 & $(0.6-10.9)$ & 2 & 3.6 & $(0.5-27.0)$ & 2 & 1.1 & $(0.2-5.7)$ \\
\hline \multicolumn{17}{|c|}{ Duration (y): } \\
\hline Mean & 8. & 9.2 & & & 6. & & & 14. & & & 3. & & & 11.0 & & \\
\hline $\begin{array}{l}1-9 \\
10+\end{array}$ & 7 & 12 & 1.5 & $(0.5-4.6)$ & 6 & 1.4 & $(0.3-5.7)$ & 3 & 1.9( & $(0.3-10.8)$ & 2 & 4.6 & $(0.5-39.4)$ & 1 & 0.8 & $(0.1-7.7)$ \\
\hline $\begin{array}{l}10+ \\
\text { Exposed to } p\end{array}$ & 1 & 4 & 2.0 & $(0.2-20.6)$ & 1 & 0.4 & $(0.0-31.6)$ & 2 & 5.5 & $(0.4-75.0)$ & 0 & 0.0 & & 1 & 1.7 & $(0.1-26.5)$ \\
\hline \multicolumn{17}{|c|}{ Exposed to perchloroethylene: } \\
\hline $\begin{array}{l}\text { Possiblef } \\
\text { Probable }\end{array}$ & $\begin{array}{l}8 \\
3\end{array}$ & $\begin{array}{r}15 \\
8\end{array}$ & $\begin{array}{l}1.5 \\
1.9\end{array}$ & $\begin{array}{l}(0.6-4.2) \\
(0.4-8.5)\end{array}$ & $\begin{array}{l}7 \\
4\end{array}$ & $\begin{array}{l}1.2 \\
1.5\end{array}$ & $\begin{array}{l}(0.3-4.6) \\
(0.2-9.5)\end{array}$ & $\begin{array}{l}4 \\
1\end{array}$ & $\begin{array}{l}2.3 \\
0.9\end{array}$ & $\begin{array}{l}(0.5-10.2) \\
(0.1-12.9)\end{array}$ & $\begin{array}{l}2 \\
2\end{array}$ & $\begin{array}{l}3.6 \\
6.4\end{array}$ & $\begin{array}{l}(0.5-27.0) \\
(0.6-68.9)\end{array}$ & $\begin{array}{l}2 \\
1\end{array}$ & $\begin{array}{l}1.1 \\
0.9\end{array}$ & $\begin{array}{l}(0.2-5.7) \\
(0.1-10.0)\end{array}$ \\
\hline \multicolumn{17}{|l|}{ Cumulative } \\
\hline $\begin{array}{l}1-29 \\
30+\end{array}$ & 4 & 8 & 2.0 & $(0.5-8.3)$ & 3 & 1.0 & $(0.1-7.0)$ & 2 & 2.0 & $(0.2-17.9)$ & $\begin{array}{l}2 \\
0\end{array}$ & 11.9 & $(1.1-124)$ & 1 & 2.0 & $\begin{array}{l}(0.2-21.7) \\
(0.1-6.8)\end{array}$ \\
\hline $30+$ & 4 & 7 & 1.2 & $(0.3-4.8)$ & 4 & 1.4 & $(0.2-8.7)$ & 2 & 2.5 & $(0.3-19.1)$ & 0 & 0.0 & & 1 & & $(0.1-6.8)$ \\
\hline
\end{tabular}

* $\mathrm{OR}(95 \% \mathrm{CI})$ adjusted for age, sex, education, study period, alcohol consumption, and cigarette smoking.

Includes cancers originating at the gastro-oesophageal junction and gastric cardia.

fIncludes people considered to have medium or higher $(>20 \%)$ probability of exposure.

Includes people considered to have high ( $>50 \%$ ) probability of exposure. 
tory of working in dry cleaning were conducted with the Mann-Whitney two sample statistic.

\section{Results}

The cases and controls were similar in mean age $(60.9 v 59.8)$ and sex distribution $(74.2 \%$ men $v 69.9 \%)$. Overall, eight of 724 controls and 16 of 1120 cases reported ever having worked in the dry cleaning industry, yielding a crude OR of 1.3 ( $95 \%$ CI 0.5 to 3.5 , table). After adjustment for alcohol, cigarettes, and the other risk factors, the OR increased to 1.6. This slightly increased risk was mostly attributable to laryngeal and oesophageal squamous cell carcinomas. For laryngeal cancer, the relative risk increased with increasing number of years employed in a dry cleaning industry (trend test $\mathrm{P}=0.14$ ). Of the five cases of laryngeal cancer, the subsite of origin was known for four; three were supraglottic (ICD-O code 161.1). Analyses restricted to supraglottic cancers resulted in an OR of 5.7 (95\% CI 1.0 to 32.1 ) in those who were ever employed in dry cleaning. Four $(57.1 \%)$ of the seven cases of cancer of the oral cavity who had worked in dry cleaning had cancer of the tongue (ICD-O code $141 \mathrm{x}$ ) in comparison with $26.4 \%$ of the non-exposed cases. The OR for cancer of the tongue associated with ever working in dry cleaning was 2.3 (95\% CI 0.4 to 12.6 ).

All but one subject had worked in dry cleaning since the $1940 \mathrm{~s}$, making the associations with ever being exposed to PCE similar to ever working in dry cleaning. When analyses were restricted to those considered to have a high probability of being exposed, the OR for all cancers was 1.9 , with most of the increase due to two exposed cases of oesophageal squamous cell carcinomas.

When cumulative exposures were examined, there was no evidence of a dose-response relation for all cancers together, for cancer of the oral cavity, or for either of the histological types of oesophageal cancer. For laryngeal cancer, the ORs for those exposed for 1-29 and $\geqslant 30$ ppm-years were 2.0 and 2.5 respectively (trend test $P=0.30$ ). Cumulative exposure analyses restricted to those considered to have a high probability of being exposed yielded no evidence of a dose-response effect for any cancer type, although the number of subjects was extremely small (not shown). In analyses in which proxy interviews were excluded, the ORs changed little.

Notable in these data is the confounding of the association with dry cleaning by alcohol consumption, and to a lesser extent, cigarette use. For example, for oesophageal squamous cell carcinomas, the crude OR for ever being exposed to PCE was 1.7 (95\% CI 0.2 to 8.5 ), whereas the alcohol adjusted OR was 3.3 ( $95 \%$ CI 0.3 to 18.8 ). This is explained by the finding that $25.4 \%$ of controls who had never worked in dry cleaning reported drinking seven or more drinks per week, compared with $12.5 \%$ (one of eight) controls who had worked in dry cleaning. The median drinks per week were 2.1 for controls who had never worked in dry cleaning, and 0.7 for controls who had $(P=0.12)$. The median number of pack-years for the groups were 15.0 for those without a history of working in dry cleaning, and 5.0 for those who had $(\mathrm{P}=0.32)$.

\section{Discussion}

The main limitation of this study is the low prevalence in the population of a history of working in dry cleaning, with the consequent low statistical power to detect a true association. This should be kept in mind in interpreting the results, which are useful mainly in the context of previous studies, and potentially, in future meta-analyses. Another limitation is the lack of direct measurements of solvent concentrations or knowledge of solvent use in the workplace. Our reliance on historical measurements from published literature to estimate individual exposure to PCE, rather than the study subjects' actual exposures, should produce non-differential misclassification of exposure, most likely resulting in a conservative bias. Any subjects exposed to PCE in other occupations would have been misclassified as unexposed in the present analysis, again yielding a conservative bias.

Some of the strengths of the study include its population based design, its inclusion of incident cases rather than deaths, the availability of detailed information on smoking and alcohol, and the ability to differentiate between histological types of oesophageal cancer, and between sites of origin in the larynx and oral cavity.

An International Agency for Research on Cancer (IARC) working group recently concluded that there was limited evidence (group 2B) that occupational exposures in dry cleaning were carcinogenic. ${ }^{1}$ The human studies that most strongly support such an association are two cohort mortality studies of dry cleaning union members, each of which found a significant twofold excess risk of death from oesophageal cancer. ${ }^{23}$ The histological type was not known in these studies; however, it can be inferred from the dates of follow up, which began in the 1940 s, that most were squamous cell carcinomas. Although the increased OR for oesophageal squamous cell carcinoma in the current report would seem to support the previous findings, the short duration of exposure among the cases and the wide 95\% CIs that include the null argue for a cautious interpretation of the findings.

The only previous evidence for an association between work in dry cleaning and laryngeal cancer is also from the same two cohort studies, with ORs of $1.3(95 \% \text { CI } 0.2 \text { to } 4.7)^{2}$ and 1.6 (95\% CI 0.3 to 4.7$).{ }^{3}$ Our study found a slightly stronger association, although one still easily explained by chance. The association with supraglottic tumours is intriguing, but was not previously hypothesised.

We found little evidence of increased risk of oral and pharyngeal cancers. Most of the slight excess risk for oral cancer (OR 1.6; 95\% CI 0.6 to 3.6) that Ruder et al found was attributable to cancer of the tongue (OR 3.5; 95\% CI 0.7 to 10.4), which is supported by our findings. ${ }^{2}$

In summary, the slight increases in risk we found could easily be explained by chance; 
nevertheless, they are consistent with previous reports of excess risks of oesophageal, laryngeal, and tongue cancer, and suggest that previous studies of dry cleaners that could not control for alcohol and cigarette use may have underestimated the relative risks of such cancers.

We appreciate the suggestions of Dr Noel Weiss, and the editoial advice of Ms Anne Morrison. This research was supported by NCI grants R01 CA30022 and R37 CA41530, NCI cooperative agreement U01 CA57949, and NCI contract N01 CN05230.

1 International Agency for Research on Cancer. LARC monographs on the evaluation of carcinogenic risks to humans. Vol 63. Iyon: IARC, 1995.

2 Ruder AM, Ward EM, Brown DP. Cancer mortality in female and male dry-cleaning workers. $\mathcal{F}$ Occup Med 1994; 36:867-74.

3 Blair A, Stewart PA, Tolbert PE, Grauman D, Moran FX, Vaught J, Rayner J. Cancer and other causes of death among a cohort of dry cleaners. Br f Ind Med 1990;47:1628.

4 Vaughan TL, Davis S, Kristal A, Thomas DB. Obesity, alcohol, and tobacco as risk factors for cancers of the esophagus and gastric cardia: adenocarcinoma versus squamous cell

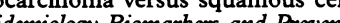
tion 1995;4:85-92.

5 Wortley P, Vaughan TL, Davis S, Morgan MS, Thomas DB. Wortley $\mathrm{P}$, Vaughan TL, Davis S, Morgan MS, Thomas DB. A case-control study of occupational risk fact

6 geal cancer. Br Ind Med 1992; 9:837, Weiss NS, Vaughan TL Nevissi AK. A case-control study of oral cancer and Nevissi AK. A case-control study of oral cancer and pre-diagnostic concentrations of se

7 National Institute for Occupational Safety and Health. Criteria for a recommended standard... occupational exposure to tetrachloroethylene (perchloroethylene). Cincinnati, $\mathrm{OH}$ : US Department of Health, Education, and Welfare, NIOSH 1976.
8 National Institute for Occupational Safety and Health. Engineering control technology assessment of the dry cleaning industry. Cincinnati, $\mathrm{OH}$ : US Department of Health and Human Services, NIOSH. 1980. (NIOSH Technical Report.)

9 Ludwig HR. Occupational exposure to perchloroethylene in the dry cleaning industry. US Department of Health and Human Services, NIOSH. Cincinnati, OH: 1981.

10 Lauwerys R, Herbrand J, Buchet JP, Bernard A, Gaussin J. Health surveillance of workers exposed to tetrachloroethylene in dry-cleaning shops. Int Arch Occup Environ Health 1983;52:69-77.

11 Monster A, Regouin-Peeters W, van Schijndel A, van der Tuin J. Biological monitoring of occupational exposure to tetrachloroethylene. Scand F Work Environ Health 1983;9: 273-81.

12 Ludwig HR, Meister MV, Roberts DR, Cox C. Worker exposure to perchloroethylene in the commercial dry cleaning industry. Am Ind Hyg Assoc $\mathcal{F}$ 1983;44:600-5.

13 Materna BL. Occupational exposure to perchloroethylene in the dry cleaning industry. Am Ind Hyg Assoc f 1985;46: 268-73.

14 Lafuente A, Mallol J. Thioethers in urine during occupational exposure to tetrachloroethylene. $B r \mathcal{F}$ Ind Med 1986; 43:68-9.

15 Imbriani M, Ghittori S, Pezzagno G, Capodaglio E. Urinary excretion of tetrachloroethylene (perchloroethylene) in experimental and occupational exposure. Arch Environ Health 1988;43:292-8.

16 Ahlborg G Jr. Pregnancy outcome among women working in laundries and dry-cleaning shops using tetrachloroethylene. Am F Ind Med 1990;17:567-75.

17 Solet D, Robins TG, Sampaio C. Perchloroethylene exposure assessment among dry cleaning workers. $\mathrm{Am}$ Ind Hyg Assoc $\mathcal{F} 1990 ; 51: 566-74$

18 Eskenazi B, Wyrobek AJ, Fenster L, Katz DF, Sadler M, Lee J, Hudes M, Rempel DM. A study of the effect of perchloroethylene exposure on semen quality in dry cleaning roethylene exposure on semen quality
workers. $A m$ f Ind Med 1991;20:575-91.

19 IT Environmental Programs. Identification of candidate facilities for study: perchloroethylene. Cincinnati, OH: NIOSH, 1992. (Contract No 200-890-2744 for NIOSH and NCI.)

20 Mutti A, Alinovi R, Bergamaschi E, Biagini C, Cavazzini S Franchini I, et al. Nephropathies and exposure to perchloroethylene in dry-cleaners. Lancet 1992;340:189-93. 